\title{
Newly Developed Psoriasis in a Patient with Telangiectasia Macularis Eruptiva Perstans and Systemic Mastocytosis Treated with Interferon
}

\author{
Tatiana Péčováa Tatiana Burjanivováb, c Bibiana Malicherovád \\ Martin Jozef Péče Igor Rohoň ${ }^{a}$ Matúš Madleňák ${ }^{a}$ Katarína Adamicováf \\ Juraj Péča \\ aDepartment of Dermatovenereology, Jessenius Faculty of Medicine in Martin, Comenius \\ University in Bratislava, Martin, Slovakia; ${ }^{b}$ Department of Molecular Biology, Jessenius \\ Faculty of Medicine in Martin, Comenius University in Bratislava, Martin, Slovakia; 'Division \\ of Oncology, Biomedical Center Martin, Jessenius Faculty of Medicine in Martin, Comenius \\ University in Bratislava, Martin, Slovakia; ${ }^{\mathrm{d} D e p a r t m e n t}$ of Clinical Biochemistry, Jessenius \\ Faculty of Medicine in Martin, Comenius University in Bratislava, Martin, Slovakia; ${ }^{\mathrm{e}}$ 1st \\ Department of Internal Medicine, Jessenius Faculty of Medicine in Martin, Comenius \\ University in Bratislava, Martin, Slovakia; 'Department of Pathology, Jessenius Faculty of \\ Medicine in Martin, Comenius University in Bratislava, Martin, Slovakia
}

\section{Keywords}

Telangiectasia macularis eruptiva perstans · Psoriasis · Mastocytosis

\begin{abstract}
The authors present a rare case of a patient with telangiectasia macular eruptiva perstans, with confirmed D816V mutation which later progressed to systemic mastocytosis confirmed by trepanobiopsy. First-line treatment - phototherapy - had to be stopped, and systemic treatment with interferon alpha-2a was initiated. The treatment was successful with regression of skin lesions as well as mast cell infiltrates in the bone marrow. However, the treatment was complicated by the onset of psoriasis lesions.
\end{abstract}




\section{Introduction}

Telangiectasia macularis eruptiva perstans (TMEP) occurs in $<1 \%$ of all cases of mastocytosis, almost exclusively in adults, in particular in obese middle-aged females, and rarely in children and adolescents $[1,2]$. Herein, we present a rare case of TMEP and systemic mastocytosis successfully treated with interferon alpha-2a with the onset of psoriasis during the treatment.

\section{Case Report}

This case reports a 58-year-old woman, BMI 38.6, nonsmoker, with no family history of mastocytosis or psoriasis, ischemic heart disease, osteoporosis, and hepatosplenomegaly. The onset of mastocytosis lesions occurred at 24 years of age, with histological confirmation at 37 years of age. Clinically, extensive, dark red to bronze brown telangiectasia lesions were present symmetrically on the arms, chest, abdomen, back, and in the lumbar region (shown in Fig. 1), with negative Darier's phenomenon.

The first line of treatment, narrow-band UVB 311-nm phototherapy, was discontinued due to appearance of melanocytic nevi, followed by treatment with antihistamines. As the diagnosis of systemic mastocytosis and TMEP was established with involvement of the bone marrow (30\% infiltration), treatment with interferon-2-alpha was initiated (6 MU 3 times per week administered subcutaneously), leading to significant regression of clinical manifestation of TMEP (shown in Fig. 2).

Six months later, psoriasiform lesions developed on the shins, elbows, back (shown in Fig. 2), and lumbosacral area, histologically confirmed as psoriasis vulgaris. Later, inverse psoriasis appeared in the axillar, perianal, and submammary region.

Skin biopsy from the lumbar region described dilated capillaries in pars reticularis and the entire pars papillaris dermis with numerous conglomerates of mutually tightly

Fig. 1. TMEP before the treatment. TMEP, telangiectasia macular eruptiva perstans.

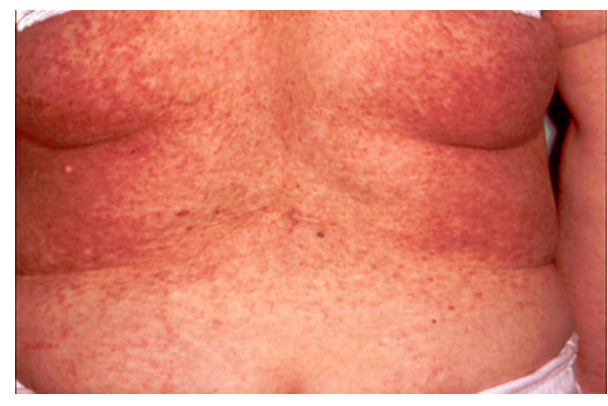

Fig. 2. TMEP after 2 years of treatment with interferon alpha$2 \mathrm{a}$, with psoriasis plaque on the back. Diffuse telangiectases of the back skin regressed by $>80 \%$. TMEP, telangiectasia macular eruptiva perstans.

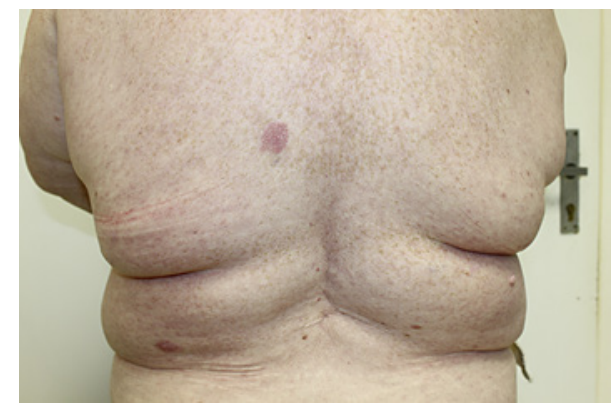


Fig. 3. Dense mast cell infiltration of the upper corium before the treatment, positive chloroacetate esterase, magnification, $\times 20$.

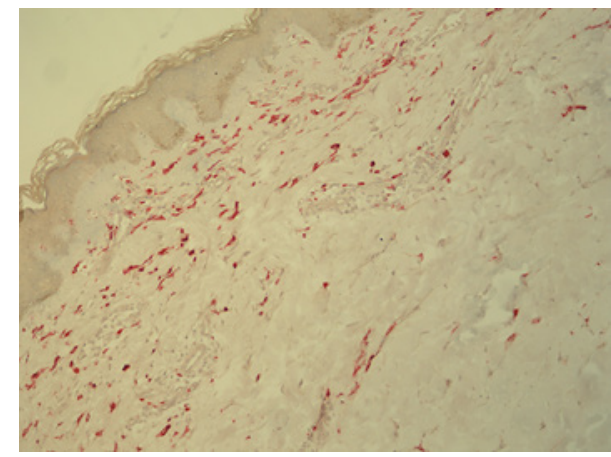

Fig. 4. Mast cell infiltration of the upper corium after 2 years of treatment with interferon alpha-2a (positive chloroacetate esterase, magnification, $\times 20$ ), with $>90 \%$ regression of mast cell infiltrates.

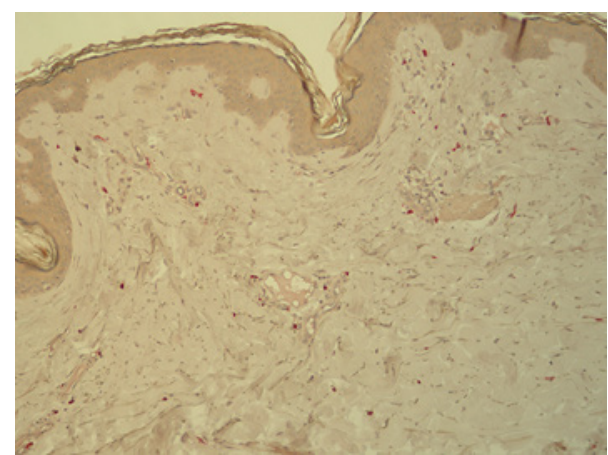

bound mast cells with oval nuclei and dense cytoplasmic granules (shown in Fig. 3). The mast cells showed cytoplasmic positivity of chloroacetate esterase and CD117 membrane positivity. There were small amounts of admixed T cells (CD3 and CD45RO) and Langerhans cells (S100 and CD1a). Repeated biopsy of the TMEP lesion during interferon therapy confirmed a marked regression of mast cell infiltrate of the dermis (shown in Fig. 4).

DNA from whole blood was isolated by using DNeasy Blood and Tissue Kit (Qiagen, Hilden, Germany). Allele-specific PCR (AS-PCR) for KIT D816V was performed in the patient's blood sample [3]. We found $D 816 \mathrm{~V}$ mutation in DNA isolated from our patient.

Ultrasonography confirmed a diffuse lesion of the liver with increased echogenicity and advanced steatofibrosis. The repeated bone marrow trepanobiopsy showed the presence of spongiosis with the image of plaque, predominantly interstitial $40 \%$ mast cell infiltration with admixture of eosinophils, plasma cells, and small lymphocytes. In areas not infiltrated with the mast cells, there was a picture of slightly hypocellular reserve hematopoiesis (due to increased fat) in the stroma with a mild stage of diffuse fibrosis. Findings from bone marrow trepanobiopsy correlated with the scintigraphic examination of the skeleton with radiopharmaceutical $99 \mathrm{mTc}-\mathrm{MDP}$. There was a D816V mutation. As a result of interferon therapy, repeated control bone marrow trepanobiopsy showed the regression of mast cell infiltrates down to the current $15 \%$.

The levels of the serum tryptase were increased $(46.1 \mathrm{ng} / \mathrm{mL}$, reference levels $0-20.0 \mathrm{ng} / \mathrm{mL}$, TriptaseImmuno CAP test). HLA typization (PCR) of psoriasis (HLA Cw 6, HLA B 27) was negative. The interferon alpha-2a treatment resulted in a decline in serum tryptase; however, increased serum levels of liver enzymes, kappa and lambda chains, kappa/lambda index, and beta 2-microglobulin still persist. Psoriatic lesions responded well to treatment with topical corticosteroids. 


\section{Discussion}

It is assumed that mutations of "stem cell factor" and its proto-oncogene c-kit receptor (CD117), such as Asp820Gly and Asp816Val [4], are involved in the mast cell proliferation and the dysregulation of mast cell function. TMEP lesions are usually located in the chest, arms, face, and other parts of the body, unilaterally or asymmetrically [5]. Morphologically, they are particularly in the form of stationary bronze-brown macules with a diameter of 2-6 $\mathrm{mm}$, defusing to erythema and at times to erythroderma, with the formation of telangiectasia, without local or systemic manifestations, while Darier's sign is hardly retrievable [6].

Histologically in a TMEP skin lesion, there is an accumulation of mast cells in the upper third of dermis in pars papillaris corii, located perivascularly at dilated capillaries [6]. Mast cells have round or oval nuclei and polyhedral shape. Because the mast cells are present only in small quantities, interpretation of histological findings of mastocytosis is often mistaken. The cells of the stratum basale epidermis show increased levels of melanin [7].

Interferons as immunomodulators may reduce IgE production and thus also mast cell proliferation, they inhibit release of histamine from mast cells after their previous antigen stimulation, and through the suppression of $\mathrm{CD}_{3} 4^{+}$bone marrow cells, they suppress the growth and propagation of mast cells. Therefore, interferons are effective for treatment of systemic mastocytosis [8].

Interferon alpha can be considered as a trigger for psoriasis by stimulating Th1 response. It increases the lymphocytotoxic activity of natural killer $\mathrm{T}$ cells and induces production of interleukin-1 in keratinocytes, which may initiate psoriasis [9]. Besides the severe form of psoriasis, other forms of psoriasis may arise during the interferon treatment as well. First signs of psoriasis usually appear after 3-5 weeks or even after 7 months after the interferon alpha treatment initiation, with the dose of $3 \mathrm{MU}$ or most often the dose of $5 \mathrm{MU}$ administered 3 times per week. In patients with pre-existing psoriasis, this can happen after a week or within 5 months [10].

Previously considered only as a part of the allergic reaction, the mast cell is possibly also playing role in the pathomechanism of chronic inflammatory skin diseases. Mast cells can interact through various mechanisms with several cells - cells of the immune system (T cells), eosinophils, and neutrophils and affect endothelial cells, keratinocytes, and sensory nerves. Involvement in the immunoregulation of psoriasis strongly suggests their production of IL-17 and TNF- $\alpha$. Mast cells accumulated in chronic psoriasis lesions show signs of activation and produce pro-inflammatory mediators that constantly potentiate inflammation [11].

Our patient presented as a typical case of TMEP with all clinical and histological manifestations of the disease, with the mutation of c-kit proto-oncogene, combined with systemic mastocytosis, accompanied with splenomegaly and $40 \%$ bone marrow mast cell infiltration prior to treatment. After 4 years of IFN treatment, all skin lesions resolved, and the mast cell infiltrate of the bone marrow decreased to $15 \%$. Psoriasis onset was a side effect of IFN treatment, managed by the topical treatment and did not require discontinuation of IFN therapy.

\section{Statement of Ethics}

All procedures adopted in this study were conducted ethically in accordance with the World Medical Association Declaration of Helsinki. Written informed consent was obtained from the patient for publication of this case report and any accompanying images. The study is exempt from ethics committee approval as the patient was treated with the standard of care using evidence-based guidelines.

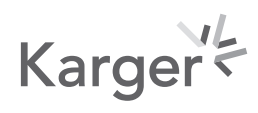




\section{Conflict of Interest Statement}

The authors have no conflicts of interest to declare.

\section{Funding Sources}

The authors did not receive any funding to conduct this research.

\section{Author Contributions}

T.P. examined the patient, collected the anamnesis, treated the patient, and participated in writing the manuscript, T.B. and B.M. examined the patient's DNA with the PCR sampling and testing, K.A. performed histological examination of the skin and bone marrow, J.P. provided his expert opinion and supervised treatment and the writing of the manuscript, M.J.P. performed and evaluated internal examinations and made the review of the literature, and I.R. and M.M. participated in the literature review and collaborated on the preparation of the manuscript.

\section{Data Availability Statement}

No datasets were generated or analyzed during the current study.

\section{References}

1 Longly J, Duffy TP, Kohn S. The mast cell and mast cell disease. J Am Acad Dermatol. 1995;4:545-61.

2 Sarkany RPE, Monk BE, Handsfield-Jones SE. Telangiectasia maculariseruptiva perstans: a case report and review of the literature. Clin Exp Dermatol. 1998;23:38-9.

3 Corless CL, Harrell P, Lacouture M, Bainbridge T, Le C, Gatter K, et al. Allele-specific polymerase chain reaction for the imatinib-resistant KIT D816V and D816F mutations in mastocytosis and acute myelogenous leukemia. J Mol Diagn. 2006;8(5):604-12.

4 Pignon JM, Giraudier S, Duquesnoy P, Jouault H, Imbert M, Vainchenker W, et al. A new c-kit mutation in a case of aggressive mast cell disease. Br J Haematol. 1997;96:374-6.

5 Gonzalez-Castro U, Luelmo-Aguilar J, Castells-Rodellas A. Unilateral facial telangiectasia macularis eruptiva perstans. Int J Dermatol. 1993;32:123-4.

6 Cattonar P, Grandi G, Plebani M, Faggian D, Falconieri G, Trevisan G. Urticaria pigmentosa in a child (telangiectasia macularis eruptiva perstans). Acta dermatovenerologica APA. 1997;6:101-6.

7 Mihm MC, Clark WH, Reed RJ, Caruso MG. Mast cell infiltrates of the skin and the mastocytosis syndrome. Hum Pathol. 1973;4:231-9.

8 Czarnetzki BM, Algermissen B, Jeep S, Haas N, Nürnberg W, Müller K, et al. Interferon treatment of patients with chronic urticaria and mastocytosis. J Am Acad Dermatol. 1994;30:500-1.

9 Funk J, Langeland T, Schrumpf E, Hanssen LE. Psoriasis induced by interferon-alpha. Br J Dermatol. 1991;125: 463-5.

10 Kim GW, Jwa SW, Song M, Kim HS, Kim BS, Kim MB, et al. Extensive psoriasis induced by pegylated interferon alfa-2a and ribavirin in the treatment of chronic hepatitis C. Ann Dermatol. 2013;25(4):479-82.

11 Harvima IT, Nilsson G, Suttle MM, Naukkarinen A. Is there a role for mast cells in psoriasis? Arch Dermatol Res. 2008;300(9):461-78. 